\title{
MONTAGEM DE UM PROTÓTIPO EXPERIMENTAL DE UMA COLUNA DE LEITO FIXO UTILIZANDO RESÍDUO DO PROCESSAMENTO DE AZEITONAS COMO ADSORVENTE
}

\author{
J. R. L. NOVAES ${ }^{1}$, C. M. S. BARBOSA ${ }^{2}$, N. C. da SILVA ${ }^{3}$, A. R. PEREIRA ${ }^{4}$, M. R. F. \\ NETO $^{5}$, C. S. S. PEREIRA ${ }^{6}$ \\ ${ }^{(1,2)}$ Discente em Engenharia Ambiental e Sanitária - USS; ${ }^{(3)}$ Discente em Química Industrial \\ - USS; ${ }^{(4)}$ Doutorando TPQB/EQ/UFRJ; ${ }^{(5,6)}$ Docente - CECETEN/USS \\ Centro de Ciências Exatas, Tecnológicas e da Natureza-USS \\ Avenida Expedicionário Osvaldo de Almeida Ramos, 280 - Vassouras, RJ - CEP: 27700-000
}

Email: crispereirauss@gmail.com

\begin{abstract}
RESUMO - As agroindústrias geram resíduos que atualmente vêm sendo estudados, devido ao seu alto poder de sorção. A indústria alimentícia de extração de azeite e processamento das azeitonas de mesa gera grande quantidade de resíduos, em média 3,5 toneladas por dia. O efluente gerado neste processo possui alto índice de turbidez, devido ao teor elevado de matéria orgânica. Tendo em vista essas características, há necessidade de enquadramento na legislação, atendendo aos parâmetros permitidos para descarte em corpos receptores. O objetivo do trabalho foi montar uma coluna de adsorção e analisar a viabilidade do uso do caroço de azeitona como material adsorvente para clarificação do efluente da própria empresa geradora deste resíduo. A coluna foi construída em material PVC, com um diâmetro de $3,9 \mathrm{~cm}$ e $58,5 \mathrm{~cm}$ de altura. Essa coluna foi recheada com caroços de azeitona triturados. A eficiência do processo de clarificação foi alcançada com a redução da turbidez do efluente em torno de $90 \%$.
\end{abstract}

\section{INTRODUÇÃO}

A geração de resíduos é uma atividade constantemente realizada pela sociedade mundial. Com a revolução industrial, a geração de resíduos tornou-se mais presente e hoje, com o consumismo desenfreado, tornou-se um dos maiores problemas ambientais. Assim, a busca por soluções para a destinação dos resíduos, aumentou significativamente, na tentativa de minimizar impactos negativos causados ao meio ambiente.

A adsorção é uma técnica de tratamento amplamente utilizada para a remoção de compostos orgânicos dissolvidos e contaminantes químicos em efluentes de difícil degradação biológica. Nos 
processos de adsorção, o carvão ativado é um dos adsorventes mais utilizados, porém apresenta alto custo. Diversas pesquisas têm buscado soluções alternativas de adsorventes de baixo custo e que apresentem menor risco ao meio ambiente, podendo citar: caroços de ameixa (Okiel et al., 2011), casca de amendoim (Zhu et al., 2009) fibras de casca de coco (Mohan e Pittman JR, 2006), casca de nozes (Kumar et al., 2010), casca de arroz (Manique et al., 2012), etc.

O setor agroindustrial é responsável por grande parcela da produção de resíduos e efluentes, oriundos do processamento de alimentos, podendo citar como exemplo a indústria de extração de azeite e de produção das azeitonas de mesa, que geram grandes quantidades de subprodutos dentre eles uma grande quantidade de caroço oriundo da etapa de descaroçamento da azeitona. Azeitonas e azeite de oliva são produtos constantes na mesa do brasileiro. O Brasil é o sétimo maior importador mundial desses produtos, principalmente de países como Argentina, Peru, Chile, Espanha e Portugal (EPAMIG, 2005).

De acordo com o texto retirado da página www.quimica.com.br, o pesquisador Germán Tenorio Rivas membro do grupo de Concentração de Sólidos e Biorremediação, do departamento de Engenharia Química da Universidade de Granada (Espanha), desenvolveu uma aplicação para os caroços das azeitonas que devido ao alto teor de conteúdo orgânico e substâncias gordurosas, seu aproveitamento era uma dor de cabeça para os produtores. Para o pesquisador, os caroços são excelentes instrumentos para a depuração de águas contaminadas por metais pesados como o cromo. O autor explica que a capacidade de absorver um metal pesado como o cromo reside na diferença de carga elétrica e em uma atração iônica. "O caroço de azeitona possui carga negativa, enquanto o metal, carga positiva; por isso, ambos os materiais atraem-se.

De acordo com Chimatti (2012), o resíduo é um dos principais problemas enfrentado pela agroindústria, geradora do efluente analisado. Esse resíduo é proveniente do processo de descaroçamento das azeitonas. A indústria possui no processo, quatro máquinas em funcionamento, cada máquina pode processar em média $19.000,00 \mathrm{Kg}$ de azeitonas inteiras por dia. De acordo com os dados fornecidos pela empresa, são gerados mais de $3.800 \mathrm{Kg}$ do resíduo por dia. A Figura 1 ilustra o caroço residual obtido após a etapa de descaroçamento.

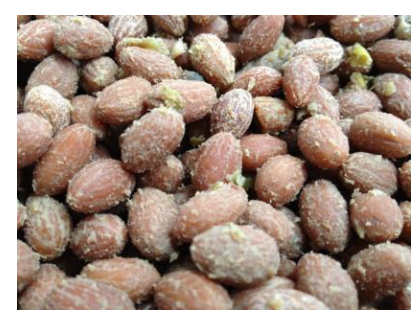

Figura 1 - Caroços de azeitona após o processo de descaroçamento

Diante desse cenário existe a necessidade de buscar novas tecnologias para minimizar os possíveis impactos causados pelas agroindústrias no meio ambiente. Neste trabalho avaliou-se a utilização do caroço de azeitona como um adsorvente natural e de baixo custo no tratamento de efluente na própria indústria de processamento de azeitonas. 


\section{MATERIAIS E MÉTODOS}

A pesquisa foi realizada no laboratório de Ciências Ambientais da Universidade Severino Sombra, onde foram realizados os ensaios de adsorção. O caroço de azeitona e o efluente utilizado foram cedidos por uma indústria de alimentos localizada na cidade de Três Rios/RJ. O efluente bruto foi coletado após o tanque de equalização da estação de tratamento de efluentes. O efluente foi armazenado em um recipiente de PVC de 5L e mantido refrigerado até posterior análise. A eficiência do processo foi medida em termos da redução da turbidez do efluente. O efluente bruto foi caracterizado conforme os parâmetros de turbidez.

\subsection{Montagem da coluna de adsorção}

O aparato experimental utilizado nos experimentos foi construído com base no trabalho de (De Freitas et al., 2013). Foi utilizado um cano de PVC com 58,4 cm de altura e $3,9 \mathrm{~cm}$ de diâmetro. Na parte inferior da coluna foi acoplado um registro com objetivo de controlar a vazão de saída do efluente para amostragem. O efluente foi adicionado à coluna através de uma bomba. Para a retenção do material adsorvente no interior da coluna utilizou-se uma tela metálica. $\mathrm{O}$ aparato experimental é ilustrado na Figura 2.

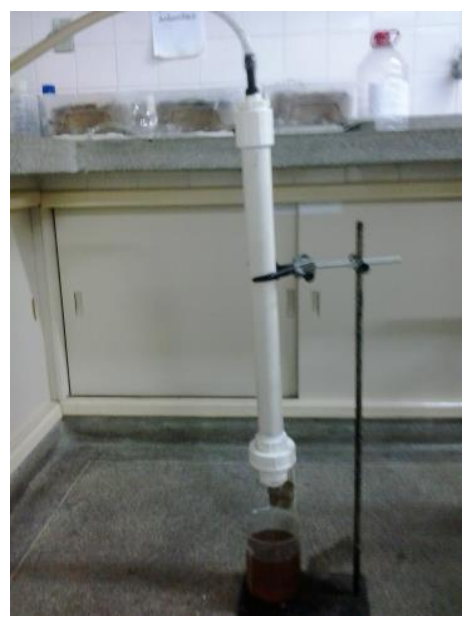

Figura 2 - coluna de adsorção

O caroço de azeitona utilizado na coluna de adsorção foi seco em estufa, a uma temperatura de $100{ }^{\circ} \mathrm{C}$ durante 4 horas e moído em moinho de pedra na Embrapa Solos. O resíduo apresentou uma densidade de $0,64 \mathrm{~g} / \mathrm{mL}$. Antes da alimentação do efluente a coluna, o material adsorvente foi lavado com água até a constatação da clarificação da água. Cerca de 5 litros de efluente foi bombeado para o interior da coluna. A adsorção ocorreu de forma descontínua. As coletas de amostras foram realizadas em intervalos de 5, 10 e 15 minutos. 


\section{RESULTADOS E DISCUSSÕES}

O efluente bruto apresentou turbidez de 475 NTU. Após o processo de adsorção o efluente apresentou uma redução do parâmetro turbidez em torno de $90 \%$. Os valores encontrados são apresentados na Tabela 1.

Tabela 1 - Efluente tratado após a adsorção

\begin{tabular}{|c|c|c|c|}
\hline Tempo (minutos) & Turbidez (NTU) & Desvio Padrão (\%) & Eficiência de Remoção \% \\
\hline 5 & 45,3 & 12,0 & 90,5 \\
\hline 10 & 33,3 & 6,8 & 93,0 \\
\hline 15 & 32,4 & 6,5 & 93,1 \\
\hline
\end{tabular}

$\mathrm{O}$ pH foi medido durante todos os ensaios e não apresentou variação significativa no ensaio, apresentando valores na faixa de 3,6 a 3,4 .

Rossini et al. (2013) investigaram o uso do pó do caroço de azeitona associado ao sistema de coagulação/floculação e flotação no tratamento do efluente da indústria de processamento de azeitonas. De acordo com os autores o tratamento reduziu em $30 \%$ os valores de turbidez e DQO do efluente tratado.

Bohli et al. (2013) estudaram a adsorção de fenol em solução aquosa utilizando caroços de azeitonas como carvão ativado. Os resultados indicaram que a ativação química do caroço de azeitona é adequada para sua utilização como um material adsorvente.

Rodriguez et al. (2008) citam em seu trabalho o potencial uso do caroço de azeitona como metal biosorvente. Blazquez et al. (2005) estudaram a viabilidade do caroço de azeitona como um adsorvente para a remoção de íons metálicos de efluentes aquosos como Cd (II) e Fiol et al. (2006) avaliaram a capacidade do mesmo em adsorver os íons, $\mathrm{Pb}$ (II), Ni (II) e Cu (II). De acordo com as pesquisas, os resultados mostraram que as partículas de menor tamanho $(0,355$ e 0,250 milímetros) do caroço foram capazes de absorver os íons metálicos. Para Souisse et al. (2005) o caroço de azeitona apresenta alta porosidade e também pode ser utilizado na forma de carvão ativado para tratamento de efluentes das indústrias têxtil.

\section{CONCLUSÃO}

As agroindústrias necessitam de uma maneira mais sustentável para destinar seus resíduos. Dessa forma, são de extrema importância que sejam criadas tecnologias eficientes para destinação de subprodutos gerados por elas. No presente trabalho o uso do caroço de azeitona utilizado como adsorvente promoveu a clarificação do efluente estudado, reduzindo a turbidez em torno de $90 \%$, demonstrando ser uma potencial alternativa para tratamento de efluentes agroindustriais. 


\section{9 a 22 de outubro de 2014 \\ Florianópolis/SC}

\section{REFERÊNCIAS}

BOHLI T, FIOL N, VILLAESCUSA I, OUEDERNI A. Adsorption on activated carbon from olive stones: kinetics and equilibrium of phenol removal from aqueous Solution. $J$ Chem Eng Process Technol 4: 165, 2013.

CHIMATTI, W. Fabricação de subprodutos Gerados a partir do Resíduo do Processo de Descaroçamento e Seleção de Azeitonas Brutas. Trabalho de Conclusão do Curso de Química Industrial. Universidade Severino Sombra, Vassouras- RJ, 2012.

DE FREITAS, M. G. N., DE SOUZA ALVES, L., DE AZEVEDO-MELEIRO, C. H., MENDES, M. F., DA CRUZ MELEIRO, L. A. Desenvolvimento de um processo contínuo para clarificação de óleo de milho em coluna de leito fixo. Revista de Ciências Exatas, 32(1), 2013.

FIOL, N., VILLAESCUSA, I., MART_INEZ, M., MIRALLES, N., POCH, J., SERAROLS, J.Sorption of $\mathrm{Pb}(\mathrm{II}), \mathrm{Ni}(\mathrm{II}), \mathrm{Cu}(\mathrm{II})$ and $\mathrm{Cd}(\mathrm{II})$ from aqueous solution by olive stone waste. Sep. Purif. Technol. 50, 132-140, 2006.

KUMAR, P. S.; RAMALINGAM, S.; SENTHAMARAI, C.; NIRANJANAA, M.; VIJAYALAKSHMI, P.; SIVANESAN, S. Adsorption of dye from aqueous solution by cashew nut shell: Studies on equilibrium isotherm, kinetics and thermodynamics of interactions. Desalination, v. 261, p. 52-60, 2010.

MANIQUE, M. C.; FACCINI, C. S.; ONOREVOLI, B.; BENVENUTTI, E. V.; CARAMÃO, E. B. Rice husk ash as an adsorbent for purifying biodiesel from waste frying oil. Fuel, v. 92, p. 5661, 2012.

MOHAN, D.; PITTMAN JR, C. U. Activated carbons and low cost adsorbents for remediation of tri- and hexavalent chromium from water. Journal of Hazardous Materials, v. 137, p. 762-811, 2006.

OKIEL, K.; EL-SAYED, M.; EL-KADY, M. Y. Treatment of oil-water emulsions by adsorption onto activated carbon, bentonite and deposited carbon. Egyptian Journal of Petroleum, v. 20, p. 9$15,2011$.

RODRIGUEZ G., LAMA A., RODRIGUEZ R., JIMÉNEZ A., GUILLÉN R., FERNÁNDEZBOLAÑOS. Olive Stones an attractive source of bioactive and valuable compounds. Bioresour Technol, 99(13):5261-9, 2009.

SIMÕES C., TORRES D., PEREIRA A., NETO M., PEREIRA C. Utilização do resíduo do processo de descaroçamento da azeitona no tratamento de efluente, 2013. Congresso Brasileiro de Engenharia Química de Iniciação Científica, 2013.

SOUISSI S.,OUEDERNI A. RATEL A. Adsorption of dyes onto activated carbon prepared from olive stones. J Environ Sci.17 (6): 998-1003, 2005.

ZHU, C.-S.; WANG, L.-P.; CHEN, W.-B. Removal of $\mathrm{Cu}(\mathrm{II})$ from aqueous solution by agricultural by-product: Peanut hull. Journal of Hazardous Materials, v. 168, p. 739-746, 2009. http://www.quimica.com.br/revista/qd467/atual/atualidades04.html

EPAMIG - Empresa de Pesquisa Agropecuária de Minas Gerais. Disponível em: http://www.epamig.br/index.php?option=com_docman\&task=doc_download\&gid=18. 